from a study of this report; many of the statements commonly found in text-books need to be revised in the light of these experiences in particular, we need to think again about protein levels and the causes of cedema.

Perhaps the most heartening paragraph in the whole report is the one dealing with rehabilitation. Although it did not prove possible to organize a follow-up of many people, in those who were seen, "weight recovery was very rapid .... and the only permanent ill-effects detectable were the few irreversible changes in the nervous system, such as spastic paraplegia and optic atrophy. The impression is strong ... that a year after release there were few ex-internees, except those prevented by age, who were not fit to return to duty in the tropics". One would like an assurance that this recovery persisted, and that there were no later breakdowns; especially one would like to have more information about those who spent four years of their childhood under these appalling conditions. About this group the report is singularly silent.

M. W. Grant

\section{MOSCOW CONFERENCE ON THE THEORY OF CHEMICAL STRUCTURE IN ORGANIC CHEMISTRY*}

$T$ HE Conference on the Theory of Chemical Structure in Organic Chemistry, called by the Chemical Science Section of the Academy of Sciences of the U.S.S.R., directs attention to the great importance of the questions that have formed the subject of discussion and have attracted the attention of the whole chemical community of our country. More than four hundred chemists, physicists and philosophers of the Academy of Sciences of the U.S.S.R., of the academies of sciences of individual republics, of scientific research institutes, and of the higher educational institutes of the Soviet Union have taken part in the Conference.

The great activity of the participants has clearly shown that the Conference was opportune and necessary and that the questions raised are of real and immediate importance. The chemists, and also physicists, of our country have not given sufficient attention to the struggle for the establishment of the dialectical-materialism world-view in chemical science and allied branches of physics, in theoretical chemistry and, in particular, in organic chemistry, and, as a result, some Soviet chemists have been ensnared by the unsound, idealistic 'theory' of resonance.

The sterile 'theory' of resonance and the blunders of the Soviet scientists who have developed this unsound conception and applied it in their work were subjected to devastating criticism by the participants of the Conference. The Conference has clearly demonstrated the soundness of the theory of the structure of organic compounds due to the great Russian scientist, A. M. Butlerov; this theory lies at the basis of the whole of modern organic chemistry. The Conference pointed out the urgent necessity of further developing Butlerov's materialistic theory of

* Resolution adopted by the Conference held on June 14, 1951 ; translated from Zhurnal obshchey khimii (Journal of General Chemistry of the U.S.S.R.), 21, 1729 (September 1951), by Dr. A. E. Stubbs. organic compounds and of studying more deeply his works and those of prominent representatives of the famous Butlerov school of organic chemists.

Having considered the report of the Committee of the Chemical Science Section of the Academy of Sciences of the U.S.S.R., the Conference notes that during the period of the Stalin five-year plans there has been created, under the leadership of the Party, of the Government, and of Comrade Stalin personally, a mighty industry of heavy organic synthesis: the first synthetic rubber industry in the world has been created; motor-fuel, synthetic fibre, dye, plastics, and other industries have been created. Recently great progress has been made in the manufacture of complex organic preparations for use in medicine and in the food, textile and other industries. The manufacture has been organized of antibiotics, antimalarials, antituberculosis and other curative preparations, flotation reagents, photosensitizers, insecticides, fungicides, etc.

The Conference notes that the progress of tho organo-chemical industry is bound up with the creative development of organic chemistry in our country. Invaluable contributions to organic chemistry have been made by such discoveries as dehydrogenation catalysis by Zelinsky, the dehydroaromatization of paraffins by Kazansky and Moldavsky, isomeric transformations of unsaturated hydrocarbons by Favorsky, the Demyanov, Nametkin, Kizhner and Arbuzov rearrangements, the Lebedev, Rodionov, Nesmeyanov and other reactions, and also by important theoretical generalizations.

The Conference notes that, side by side with these fruitful trends in the theory of chemical structure, there has been a spread of unsound views that are perversions of Butlerov's teaching. In a number of monographs and taxt-books on inorganic chemistry and the theory of molecular structure, the name of Butlerov, as the creator of structural theory, has been suppressed, and the work of Russian chemists in the development of theoretical organic chemistry has not been assigned its true importance. In recent years there has been a spread in organic chemistry of a concept developed by Anglo-American scientists - the so-called 'theory' of resonance (Pauling) or mesomerism (Ingold). 'This 'theory', which presents a multistructural view of the molecule, is directly opposed to the basic thesis of Butlerov's theory.

Though unsound in method, physically untenable, and sterile, the concept of resonance or mesomerism has unfortunately found supporters among Soviet scientists (such as the following corresponding members of the Academy of Sciences of the U.S.S.R. : Ya. K. Syrkin, M. E. Dyatkina, M. V. Volkenshteyn, A. I. Kiprianov and others). These scientists, in disseminating the mechanistic and idealistic concept of resonance, tried to cover the invalidity of this concept by references to its alleged basis in quantum mechanics and invoked it to explain all the facts and laws of chemistry. The 'theory' of resonence or mesomerism was taken up in an uncritical fashion also by other Soviet scientists indicated in the report. The spreading of this 'theory' has done harm to Soviet chemistry. It has diverted the efforts of chemists into useless, pseudoscientific directions and created a harmful illusion of explaining many facts and laws, which are in reality not explained at all ; it has tried to create an appearance of well-being in the matter of the development of the theory of chemical structure, and, in fact, has held up its further development. 
The Conference notes that Ya. K. Syrkin, M. E. Dyatkina, M. V. Volkenshteyn, A. I. Kiprianov and others now acknowledge the invalidity and sterility of this 'theory'. The Conference puts on record also that in their addresses in the present discussion Ya. K. Syrkin, M. E. Dyatkina, M. V. Volkenshteyn and A. I. Kiprianov did not give a reasoned criticism of the 'theory' of resonance or mesomerism and a detailed analysis of their serious methodological and ideological errors. The Conference considers that the statements of Ya. K. Syrkin and M. V. Volkenshteyn concerning their ignorance of the works of A. M. Butlerov when compiling monographs on the nature of the chemical bond and of the structure of molecules are unsatisfactory.

One of the main causes that have led to the spreading of the idealistic 'theory' of resonance in Soviet scientific literature has been the insufficient development of scientific criticism among Soviet chemists, who have not promptly seen the unsoundness of this concept and who have not given sufficient attention to the methodology of Soviet chemical science. The decision of the Central Committee of the Communist Party regarding ideological questions has mobilized the attention of the Soviet chemical community to questions of the methodology of science and has helped to reveal errors present in chemistry and to mark out the future path of development of chemical science on the basis of the uniquely correct dialectical-materialistic world-view. The Conference notes the insufficient attention paid by Soviet philosophers to the methodological questions of theoretical chemistry, which, in particular, has been reflected in the fact that the idealistic nature of the concept of resonance was first exposed, not by philosophers, but by chemists.

The Conference approves the main theses of the report presented by the Committee of the Chemical Science Section of the Academy of Sciences of the U.S.S.R., in which the present state of chemical structural theory is analysed, the essentially idealistic nature of the 'theory' of resonance or mesomerism is shown, the errors of certain Soviet scientists are revealed, and the ways for the further development of Butlerov's teaching are marked out.

The Conference considers it necessary to point out also a number of serious defects in the report of the Committee. Thus, it is not shown in the report that the ideological perversions in matters of chemical theory are closely related to the hostile theories in biology and physiology, and that, taken together, these present $a$ united front in the fight of reactionary bourgeois ideology against materialism. In the report the progress of Soviet organic chemistry has not been fully characterized. Insufficient attention has been given to the kinetics of chemical processes, to the influence of the medium, and to the nature of the chemical reagents. Little light is thrown on the chemistry of free radicals and the mechanism of very important intramolecular rearrangements. The report considers only the better-known types of mutual interaction of atoms in the molecule, and these do not at all exhaust the various possibilities in this phenomenon. The terminology of the different type of mutual interaction cannot be regarded as finally established.

The Conference considers that it is essential to intensify work on the development of the theory of organic chemistry by all possible means. The leading line in organic chemistry is that of synthesis, which is assnciated with the investigation of the structure and properties of organic substances, including natural substances, by the methods of synthetic organic chemistry. It is in chemical synthesis that the link between theory and practice is most clearly manifest. Also, in synthetic work structural theory is being constantly verified and expanded, and its field of application is being widened. Along the line of synthesis, structural theory finds new stimuli to development.

The Conference notes that the most important problem of theoretical organic chemistry is the creative development of Butlerov's teaching and the deepening and widening of his main theses in the light of modern views on the structure of matter. The development of theoretical organic chemistry and, above all, of chemical structural theory must proceed in a state of positive struggle against idealistic and mechanistic theories in chemistry on the basis of the world-view of dialectical materialism.

It is essential to concentrate the attention of Soviet scientists on the deepening and widening of our knowledge of the chemical structure of matter and on the development of the theory of the interactions of atoms in the molecule. It is essential to investigate problems on the dependence of the reactivities of molecules on their structures and on the medium. The study of elementary processes and also of the mechanism and kinetics of reactions is of extreme importance. The study of the dependence of the chemical, physical, physiological and other properties of organic substancos on their structures is also of the greatest importance.

In order to solve the problems of the theory of chemical structure it is essential not only to use the chemical methods of investigation that have so brilliantly justified themselves, but also to make more use of the achievements of neighbouring fields of work, particularly those of contemporary physics with all the richness of its experimental and theoretical methods. In connexion with this the Conference notes the withdrawal of the majority of physicists from participation in the struggle for the creation of the foremost theory of chemical science. It is also unsatisfactory that practically none of the leading theoretical physicists have taken part in the work of the present C unference.

The Conference puts on record that physical methods of investigation are not yet sufficiently widespread in organic chemistry and considers it essential that wide use should be made of spectro. scopic, electronographic, mass-spectroscopic, and other methods of studying the structure and properties of organic compounds. The problems of the develop. ment of the theory of chemical structure demand the working out of the above and of new physical and physicochemical methods of investigation, in their application to the specific problems. The Conference calls on physicists and physical chemists to take an active part in developing these methods.

The Conference notes also the extremely inadequate part taken by theoretical physicists in the develop. ment of quantum chemistry. It is essential that Soviet theoretical physicists and mathematicians should take a most active part in the working out of problems of theoretical chemistry and quantum. mechanical calculation. Only by the joint labours of chemists and physicists will the theory of chemical structure be transformed into the quantitative theory that A. M. Butlerov has called for.

It is essential to get more Soviet monographic literature published on questions of theoretical 
chemistry. A very important problem is the writing and publishing of new text-books on organic chemistry that correctly portray the present state of chemical science. It is essential to speed up the issue of the works of our classical chemists and, particularly, of the complete works of A. M. Butlerov and of V. V. Markovnikov.

The Conference notes that the Chemical Science Section of the Academy of Sciences of the U.S.S.R., and also scientific institutes and institutes of higher education, must pay more attention to theoretical chemistry and to questions concerning the ideological basis of chemical theories and must intensify their struggle against the infiltration of idealistic 'theories' that are foreign to Soviet science.

The Conference recommends :

(1) The prompt publishing (not later than the end of 1951) of the shorthand report of the Conference.

(2) Wide publicizing of the results of the Conference in scientific journals.

(3) That arrangements should be made to publish discussions on the development of the theory of chemical structure in organic chemistry in the scientific journals-in particular, in the Journal of General Chemistry, the size of the journal being increased for this purpose.

(4) The speeding up of the publishing of new textbooks on organic chemistry that correctly portray the present state of chemical science, also of Soviet monographs on questions of theoretical chemistry.

(5) That the Chemical Science Section of the Academy of Sciences of the U.S.S.R. should periodically call conferences on the most important questions of organic chemistry and should invite specialists from allied sciences (physicists, philosophers, biologists, etc.) to attend.

The Conference calls on chemists, and also on scientists working in allied fields of physics, to take up the further creative development of A. M. Butlerov's theory of chemical structure on the basis of dialectical materialism, guided by the great works of I. V. Stalin and by his directions concerning the role and significance of progressive science in the evolution of society and of the role and significance of criticism in the evolution of science. The Conference calls on Soviet chemists to take all possible steps for the further advancement of theoretical chemistry and for the wide utilization of the results of scientific work for the national economy.

Under the guidance of the party of Lenin and Stalin, Soviet chemists will honourably carry out the directions of the great leader of the workers, the scientific genius, Iosif Vissarionovich Stalin.

\section{OBITUARIES}

\section{Mr. J. McC. Black}

IT is with regret that we learn of the death in Adelaide on December 3 of John McConnell Black, the doyen of Australian botany, in his ninety-sixth year. Born in Scotland on April 28, 1855, at Wigton, Black was educated at Wigton Grammar School, the Edinburgh Academy, Taunton College School, where other devotees of natural science have been trained, and afterwards at Dresden. At the outset of his career he joined the staff of the British Linen Company's Bank; but at the age of twenty-two he migrated to South Australia, where, in the Baroota district, he spent five years farming. For the next twenty years he served as a reporter on the staff of the Register and Advertiser of Adelaide. When, in 1902, he retired from Press work, he devoted himself to the study of the local flora, a subject which he made peculiarly his own. In 1909 there appeared his "Naturalised Flora of South Australia", which included descriptions of 368 species. Thirteen years later, when Black had already attained the age at which most men are thinking of retirement, there appeared the first part of what has become the standard flora of South Australia. This contained generic and specific descriptions of all the then known indigenous species and established aliens among the vascular plants. Two years later, namely, in 1924, the second part was published, the third appeared in 1926 and the entire work of seven hundred pages was completed in 1929, embodying clear and adequate descriptions of nearly 2,500 species. In appreciation of this outstanding achievement, largely based on his own original work, Black received a number of recognitions. He was awarded the Verco Medal of the Royal Society of South Australia and became president of that body in 1933. In the same year Black was elected an associate of the Linnean Society of London, and the Australian and New Zealand Association for the Advancement of Science awarded him the Mueller Memorial Medal. He thus joined the eminent company of Douglas Mawson, Leonard Cockayne and Wood Jones, all fellows of the Royal Society of London who were his immediate predecessors as recipients of the Medal.

When $I$ visited Mr. Black in Adelaide he was, at the age of ninety-four, remarkably active both in mind and body and might easily have passed for a contemporary of a man twenty-five years his junior. Then, and almost to the time of his death, Black was working on the second edition of his flora. Parts 1 and 2 have already appeared, and on the very day before Black died he had completed the revision of the manuscript for Part 3 up to the Plumbaginaceæ.

Thus botanical science loses one more of those gifted and distinguished amateurs who have often done so much to enlarge our knowledge of the floras and faunas of the world's surface.

\section{E. J. SALISBURY}

\section{Sir Fred Clarke}

Srr Fred Clarke, who died suddenly at his home in London on January 6, played a notable part in the promotion of higher studies in education in Great Britain. Born and bred in Oxfordshire, he was professor of education for five years in Scuthampton, eighteen years in Cape Town, and five years in McGill, before he became, in 1936, professor and director of the Institute of Education in London. It is not surprising that an outstanding feature of his tenure of that office was the development of strong ties between educationists in the older Dominions and the Institute. Under his leadership the Institute became a centre for the exchange of educational ideas and experience for the whole Commonwealth.

He took an active part in many important educational movements during the war pericd. He was an active member of the National Union of Teachers. As a member of the McNair Committee he was a strong advocate of the participation of the universities in teacher training. It was largely as the result of his inspiration that the National Foundation for Educational Research came into being. He was the first 